Proceedings

\title{
Aerosol/Ink Jet Printing Technology for High-Temperature MEMS Sensors ${ }^{\dagger}$
}

\author{
Alexey A. Vasiliev ${ }^{1,2},{ }^{,}$, Anton V. Nisan ${ }^{3}$ and Nikolay N. Samotaev ${ }^{4}$ \\ 1 Kurchatov Complex of Physical and Chemical Technologies, National Research Center Kurchatov \\ Institute, Moscow 123182, Russia \\ 2 Sensor Laboratory, ITMO University, Saint-Petersburg, Russia \\ 3 LLC RIIIT, Ostec Group, Moscow, Russia; anton.nissan@ostec-group.ru \\ 4 National Research Nuclear University “MEPhI”, Moscow, Russia; samotaev@mail.ru \\ * Correspondence: A-A-Vasiliev@yandex.ru; Tel.: +7-903-194-9551 \\ + Presented at the Eurosensors 2017 Conference, Paris, France, 3-6 September 2017.
}

Published: 18 August 2017

\begin{abstract}
In this work we present the results on the application of additive technology that is aerosol and ink jet technique for the fabrication of high-temperature metal oxide gas sensors. The application of thin $(12 \mu \mathrm{m})$ alumina membrane, aerosol jet printing of Pt microheater (line width 40-60 $\mu \mathrm{m}$ ), printed sensing layer made of nanocristalline tin dioxide based material, laser cutting of the membrane enabled the fabrication of full-printed cantilever-shaped high-temperature sensor with optimal power consumption $\left(\sim 80 \mathrm{~mW}\right.$ at $\left.450{ }^{\circ} \mathrm{C}\right)$ applicable in wireless instruments for the detection of combustible and toxic gases including methane.
\end{abstract}

Keywords: additive technology; aerosol and ink jet printing; high-temperature full printed sensor; metal oxide sensors; thermocatalytical sensor

\section{Motivation}

We present an overview of the results obtained with the application of aerosol and ink jet technologies for the fabrication of high temperature (up to $400-500{ }^{\circ} \mathrm{C}$ ) gas, flow, and temperature sensors. The application of jet printing in combination with ceramic MEMS structures based on thin alumina, LTCC and yttria stabilized zirconia (YSZ) membranes enables the fabrication of cost efficient devices with thermal characteristics compatible with those of silicon based MEMS.

The metallic inks with $\mathrm{Pt}, \mathrm{Au}$, and $\mathrm{Ag}$ nanoparticles can be printed over these ceramic membranes giving stable Pt microheater working up to $500^{\circ} \mathrm{C}$. The nanoparticle sensing layers based on metal oxide semiconductors are printed using the same technique giving efficient semiconductor and thermocatalytic gas sensors. The main field of application of such sensors, in addition to normal working condition devices, is high temperature application in car industry, heavy accident and combustion processes monitoring.

The development of ceramic MEMS technology with jet printed functional elements of the sensor are very important now, because recent technology of silicon MEMS for the fabrication of low power consuming semiconductor gas sensor (Fondazione Bruno Kessler (FBK, Trento, Italy, Figure 1), AMS (Premstaetten, Austria), Figaro (Osaka, Japan)) or polyimide substrate [1] have evident disadvantages due to restricted annealing and working temperature (about $300-350{ }^{\circ} \mathrm{C}$ for both microhotplate, and $450^{\circ} \mathrm{C}$ for FBK's unit). Another problem is the application of expensive and sophisticated equipment in silicon technology and the use of sputtering processes in the fabrication of noble metal $(\mathrm{Pt}, \mathrm{Au})$ layers deposition. The third problem is low flexibility of traditional microelectronic manufacturing process leading to difficulties in the fabrication of different 
modifications of sensors using the same process. These problems make the silicon technology hardly usable in sensor production.

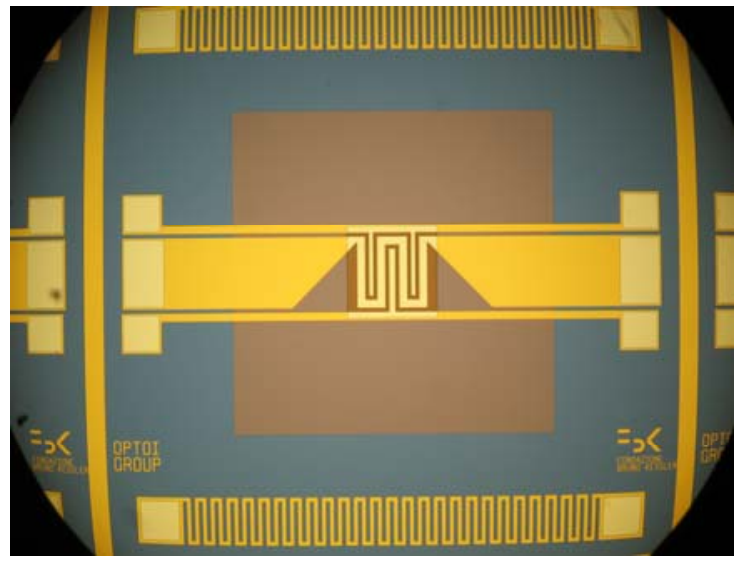

Figure 1. Pt microheater on $\mathrm{SiO}_{2} / \mathrm{Si}_{3} \mathrm{~N}_{4}$ membrane. Heater size is of $\sim 300 \times 300 \mu \mathrm{m}$, maximum sensor working temperature is of $450{ }^{\circ} \mathrm{C}(\mathrm{FBK} / \mathrm{NRC} \mathrm{KI}[2])$.

\section{Results and Discussion}

We developed the technology of thin ceramic membranes usable in highly-efficient ceramic MEMS devices operating at temperature up to $450-500{ }^{\circ} \mathrm{C}$. The material of membrane is $\mathrm{Al}_{2} \mathrm{O}_{3}, \mathrm{LTCC}$, or YSZ (10-20 $\mu \mathrm{m}$ thick). Membrane is stretched on rigid frame. The substrate with thin membranes is adopted for the group technology, because the substrate contains many sensor elements (Figure 2).

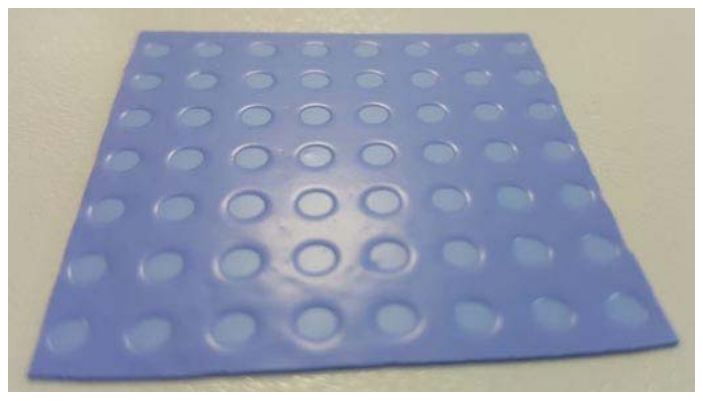

Figure 2. $20 \mu \mathrm{m}$ thick and $3 \mathrm{~mm}$ in diameter LTTC membranes stretched on rigid $100 \mu \mathrm{m}$ LTCC frame prepared for Pt printing using aerosol jet technology.

The heater is fabricated using ink or aerosol jet printing with Pt nanoparticle. Typical particle size of these inks is of 3-8 $\mathrm{nm}$. The ink is made by suspension of metal nanoparticles in solvent with viscosity of $\sim 10 \mathrm{cP}$ (typically, ethylene glycol). After sintering, this print gives a microheater stable at temperature up to $500^{\circ} \mathrm{C}$.

Power consumption of the sensor made by ink jet printing is of $\sim 70 \mathrm{~mW}$ at $450{ }^{\circ} \mathrm{C}$ (Figure 3), this is comparable with Si-based MEMS. The power consumption of the microheater with aerosol jet printed microheater is a little higher, $\sim 80 \mathrm{~mW}$, due to higher heat conductivity of more dense Pt print. Cantilever shaped microhotpalate improves the stability of the microheater at temperature cycling. It is made by cutting by fibre optic laser $(20 \mathrm{~W})$. The view of the full-printed microsensor with deposited sensing layer made of Pd-doped tin dioxide (specific surface area of about $100 \mathrm{~m}^{2} / \mathrm{g}$ ) is presented in Figure 4. The chip size is of $6 \times 6 \mathrm{~mm}$, membrane diameter is of $3 \mathrm{~mm}$. Hot area of the microheater is of about $250 \times 250 \mu \mathrm{m}$. 


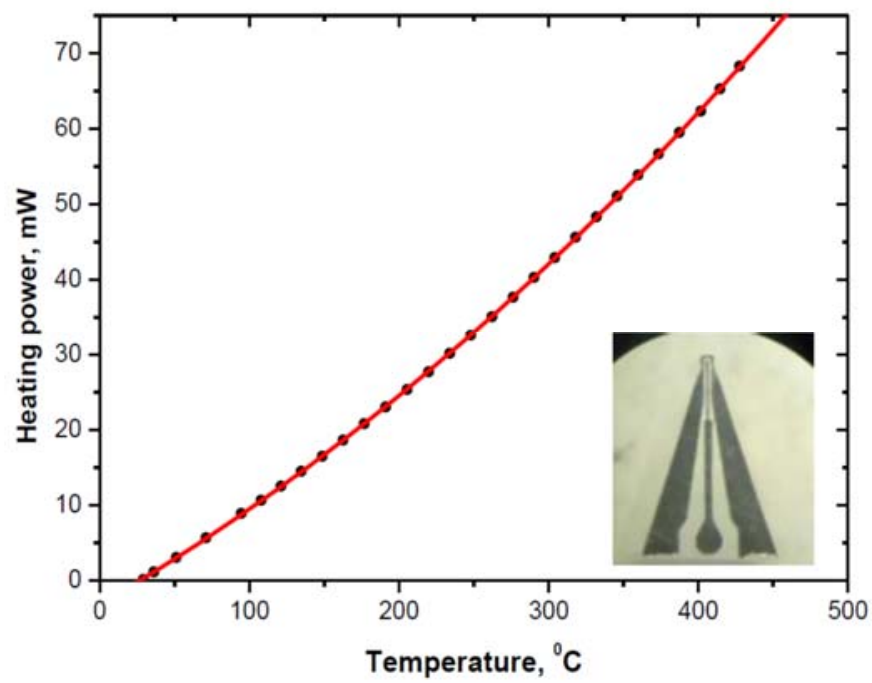

Figure 3. Power consumption of microheater on $12 \mu \mathrm{m}$ alumina ceramic film as a function of microhotplate temperature. The microheater view is given on close-up photo.

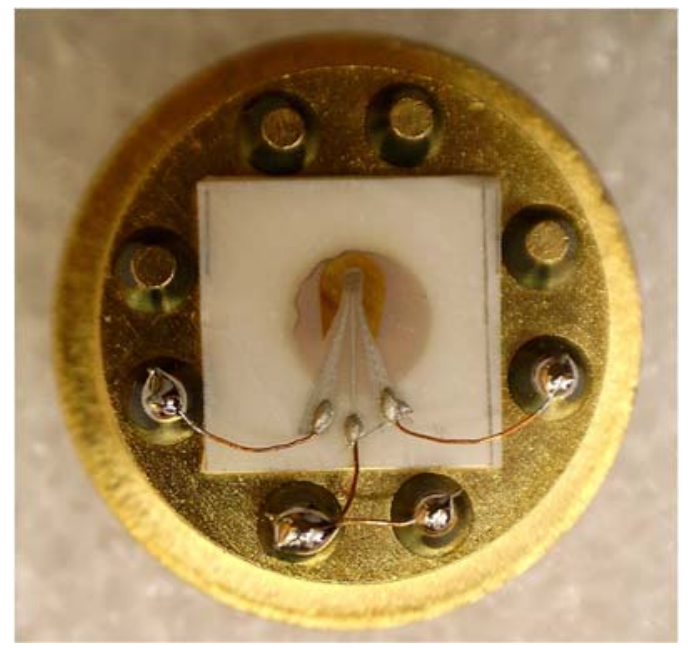

Figure 4. Full printed high-temperature gas sensor made of $12 \mu \mathrm{m}$ thick alumina. Power consumption is of $\sim 80 \mathrm{~mW}$ (continuous heating up to $450{ }^{\circ} \mathrm{C}$ ) and about $1 \mathrm{~mW}$ (pulsing heating with duty cycle of $1 \%$ ). Cantilever-type sensor is adopted for autonomous and wireless gas analyzers.

The temperature cycling enables an improvement of sensor selectivity (Figure $5 \mathrm{~A}, \mathrm{~B}$, response to $\mathrm{CO}$ and $\mathrm{H}_{2}$, respectively [3]) and a decrease in power consumption down to $<1 \mathrm{~mW}$.

The deposition of metal oxide nanoparticle semiconductor or catalytic sensing layer of chemoresistive of thermochemical gas sensors is possible using the same printing technique. The sensors demonstrate usual response to gases, it is equal, for example, to factor of 7-10 at methane concentration of 1 vol. \%. Detection limit of selective measurement of $\mathrm{CO}$ and $\mathrm{H}_{2}$ is of about $1 \mathrm{ppm}$. In the example presented in Figures 5 and 6 the sensing layer containing tin dioxide doped with $\mathrm{Pd}$ is first heated to $450{ }^{\circ} \mathrm{C}$ for $0.5 \mathrm{~s}$. At this temperature palladium is oxidized and forms palladium oxide. At low temperature part of the measurement cycle $\left(110^{\circ} \mathrm{C}, 2.5 \mathrm{~s}\right)$ palladium oxide is consumed to the oxidation of $\mathrm{CO}$ molecules. This temperature is sufficient for fast oxidation of carbon monoxide, but not sufficient for the oxidation of hydrogen with palladium oxide (Figure 5B). 

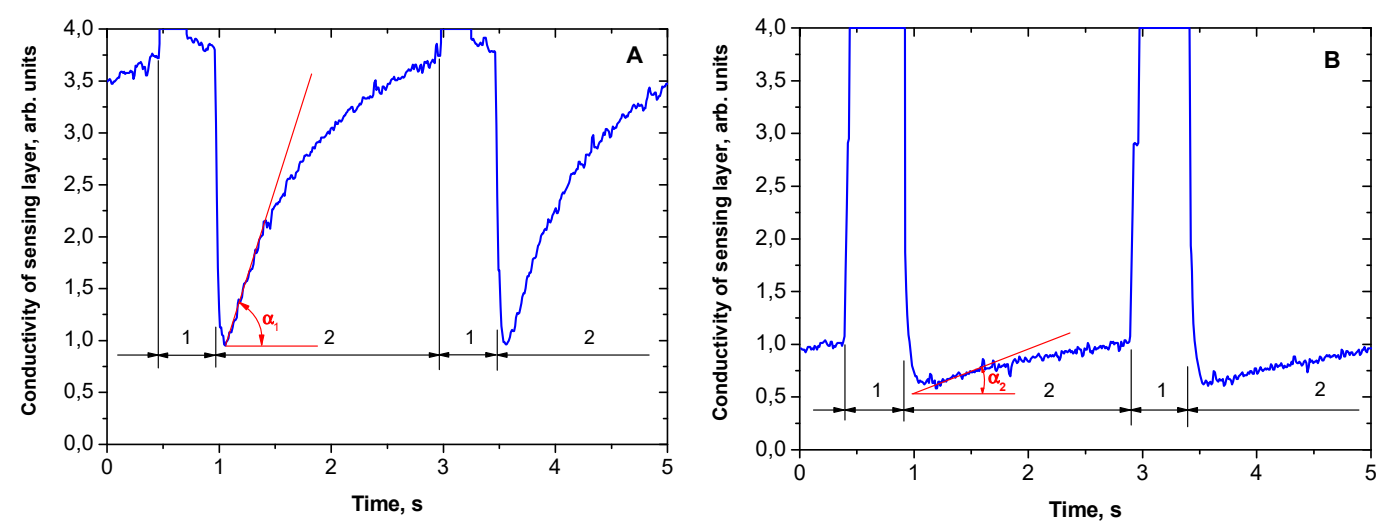

Figure 5. (A) Response of MEMS based sensor to $3 \mathrm{ppm}$ of $\mathrm{CO}$. Sensing material is $\mathrm{SnO}_{2}(10 \mathrm{~nm}$ particles $)+3 \mathrm{wt} . \%$ of $\mathrm{Pd}$. Measurement cycle is $450{ }^{\circ} \mathrm{C}(0.5 \mathrm{~s})+110{ }^{\circ} \mathrm{C}(2.5 \mathrm{~s})$. The slope of the curve $\left(\tan \alpha_{1}\right)$ is proportional to $\mathrm{CO}$ concentration. (B) Response of MEMS based sensor to $3 \mathrm{ppm}$ of $\mathrm{H}_{2}$. Sensing material and measurement cycle are the same as those in (A). The slope of the curve $\left(\tan \alpha_{2}\right)$ is proportional to $\mathrm{H}_{2}$ concentration. Selectivity factor for the $\mathrm{CO} / \mathrm{H}_{2}$ is equal to about 10 , that is the ratio of slopes at the same concentrations of $\mathrm{CO}$ and $\mathrm{H}_{2}\left(\tan \alpha_{1} / \tan \alpha_{2}\right) \approx 10$.

Smart module fabricated for controlling ceramic MEMS sensors are developed to assure plugand-play operation mode of sensor units. The smart sensor unit (Figure 6) is, in fact, a complete measuring instrument with microprocessor realizing pre-calibration of the sensor, The main advantage of such unit is the possibility of hot replacement of the unit with calibrated in laboratory ones.

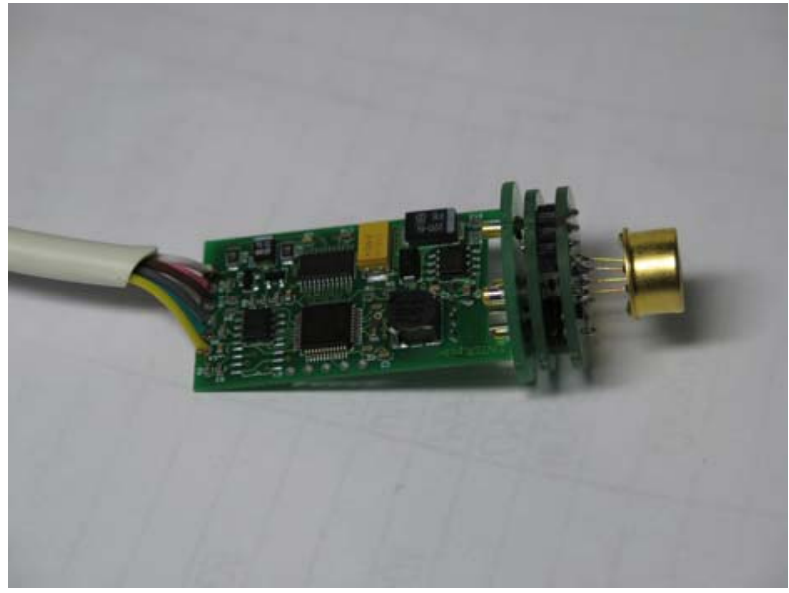

Figure 6. Smart sensor unit with gas sensor in TO-8 packaging. The round board is a smart unit with UART interface enabling temperature control of the sensor and providing all information about concentration of gas, type of sensor, enabling compensation of ambient humidity, etc. Diameter of this board is of $25 \mathrm{~mm}$.

Conflicts of Interest: The authors declare no conflict of interest.

\section{References}

1. Rieu, M.; Camara, M.; Tournier, G.; Viricelle, J.P.; Pijolat, C.; de Rooij, N.F.; Briand, D. Fully inkjet printed $\mathrm{SnO}_{2}$ gas sensor on plastic substrate. Sens. Actuators B 2016, 236, 1091-1097.

2. Vasiliev, A.A.; Pisliakov, A.V.; Sokolov, A.V.; Polovko, O.V.; Samotaev, N.N.; Kujawski, W.; Rozicka, A.; Guarnieri, V.; Lorenzelli, L. Gas Sensor System for the Determination of Methane in Water. Procedia Eng. 2014, 87, 1445-1448. 
3. Vasiliev, A.A.; Pisliakov, A.V.; Sokolov, A.V.; Samotaev, N.N.; Soloviev, S.A.; Oblov, K.; Guarnieri, V.; Lorenzelli, L.; Brunelli, J.; Maglione, A.; et al. Non-silicon MEMS platforms for gas sensors. Sens. Actuators B 2016, 224, 700-713.

(c)

(C) 2017 by the authors. Submitted for possible open access publication under the terms and conditions of the Creative Commons Attribution (CC BY) license (http://creativecommons.org/licenses/by/4.0/) 